\title{
Coat/Tether Interactions-Exception or Rule?
}

\author{
Saskia Schröter, Sabrina Beckmann and Hans Dieter Schmitt*
}

Neurobiology, Max Planck Institute for Biophysical Chemistry, Göttingen, Germany

Coat complexes are important for cargo selection and vesicle formation. Recent evidence suggests that they may also be involved in vesicle targeting. Tethering factors, which form an initial bridge between vesicles and the target membrane, may bind to coat complexes. In this review, we ask whether these coat/tether interactions share some common mechanisms, or whether they are special adaptations to the needs of very specific transport steps. We compare recent findings in two multisubunit tethering complexes, the Dsl1 complex and the HOPS complex, and put them into context with the TRAPP I complex as a prominent example for coat/tether interactions. We explore where coat/tether interactions are found, compare their function and structure, and comment on a possible evolution from a common ancestor of coats and tethers.

OPEN ACCESS

Edited by:

Anne Spang,

Biozentrum, University of Basel,

Switzerland

Reviewed by:

Benjamin S. Glick,

University of Chicago, USA

Frederick Hughson,

Princeton University, USA

*Correspondence:

Hans Dieter Schmitt

hschmit@mpibpc.mpg.de

Specialty section:

This article was submitted to

Membrane Traffic,

a section of the journal

Frontiers in Cell and Developmental

Biology

Received: 18 January 2016 Accepted: 25 April 2016

Published: 17 May 2016

Citation:

Schröter S, Beckmann S and Schmitt HD (2016) Coat/Tether Interactions-Exception or Rule?

Front. Cell Dev. Biol. 4:44.

doi: 10.3389/fcell.2016.00044
Keywords: vesicle trafficking, coat complexes, protocoatomer, coated vesicles, tethering complex

\section{INTRODUCTION}

In eukaryotic cells, vesicles pass material from one membrane compartment to the other. The cells use elaborate systems of cytoplasmic factors to control the luminal content as well as membrane constituents of the different vesicles (Rothman and Orci, 1992). Factors on the cytosolic side of vesicles and target membrane also impose directionality to the transport process. This is achieved through the recognition of the cargo by cargo receptors at the donor membrane and through the correct identification of the vesicle at the target membrane. Both cargo and vesicle recognition are controlled by small GTPases. GTPases of the ARF family control the cargo selection by coat complexes, while GTPases of the Ypt/Rab family are required for the fusion of vesicles with the appropriate target membrane (Behnia and Munro, 2005).

The main players during vesicle formation are coat complexes. They consist of soluble proteins and are recruited from the cytosol by cargo molecules. The coat formation leads to the bending of the donor membrane and, finally, vesicle release. Members of the SNARE family of membrane proteins are among these cargo molecules (Kuehn et al., 1998; Rein et al., 2002; Lee et al., 2005). They are the actual catalysts of membrane fusion (Söllner et al., 1993). Thus, SNARE proteins have two roles, one in vesicle formation and one in vesicle fusion. The packaging of specific SNAREs into vesicles is one important means to convey vesicle identity and ensure the fusion at the correct target membrane: Each transport step in the cell uses a specific set of SNAREs (McNew et al., 2000). The formation of helical bundles from SNAREs on vesicle and target membrane provides the energy to fuse the apposed membranes. However, SNAREs are not sufficient to guarantee that vesicles find their right target membrane (Brandhorst et al., 2006). Instead, additional components are recruited, often by the combined action of SNAREs and GTPases. These so-called tethering factors are thought to mediate the first contact between membranes that are bound to fuse (Cao et al., 1998; Whyte and Munro, 2002). They bind to proteins on opposite membranes, and at least some of these tethering factors also can bind specific phospholipids directly. Whether 
the tethering factors in fact form bridges between two different membranes and thus represent real tethers has not been shown for all putative tethering factors (Brunet and Sacher, 2014).

All SNAREs share a strongly conserved core structure, and the tetrameric SNARE complexes assemble mostly in a 3:1 ratio from three SNAREs on the target membrane and one SNARE on the vesicle membrane. Compared to SNAREs, the tethering factors are a much more heterogeneous group of proteins. In particular, the number of subunits making up multisubunit complexes ranges from 3 to 10 and cannot be identified by conserved sequence motifs or easily recognized by Hidden Markov model profiles, as is the case for SNARE proteins (Kloepper et al., 2007). Some Golgi-associated tethering factors are homodimers made up of long coiled-coil proteins ( $\mathrm{Yu}$ and Hughson, 2010).

Tethering factors (or complexes) interact with SNAREs and/or GTPases to control the specificity of vesicle fusion. In recent years, however, a number of papers came out where evidence was presented that tethering complexes can also interact with coat complexes (Trahey and Hay, 2010; Angers and Merz, 2011). This indicates that cells may use the coats not only for vesicle budding, but they may also keep them as stick-on labels that carry address information.

Beside the coat/tether interactions discussed below in more detail, evidence was presented for a number of other coat/tether interactions. Most of them involve interactions of the COPI coat and different Golgi tethering factors: In yeast, the Trs120p subunit of Golgi tether TRAPP II co-purifies with the COPI subunit $\alpha$-COP, while experiments with the homologous subunit of the mammalian TRAPP II complex showed interaction with $\gamma$-COP but not $\varepsilon$-COP (Yamasaki et al., 2009). $\gamma$-COP in yeast (Sec21p) is also the interacting partner of the intra-Golgi COG tethering complex (Suvorova et al., 2002). Analogously, $\beta$-COP co-purifies with Cog3 from mammalian cells (Zolov and Lupashin, 2005). A non-COPI/tether interaction was observed in mammalian cells, where the TGN-localized tether Rab6IP1 (Rab6 interacting protein 1) interacts with the retromer component SNX1 (sorting nexin 1; Wassmer et al., 2009). An overview of currently known coat/tether interactions is given in Figure 1.

This review explores whether coat/tether interactions were a fundamental feature of primordial tethering complexes in early eukaryotic cells, or whether they developed independently. We will focus on three prominent coat/tether interactions for our analyses: The interaction of (i) the COPI coat and the Dsl1 complex involved in Golgi to ER retrograde transport, (ii) the AP3 coat and the HOPS complex, an interaction that mediates direct transport of transmembrane proteins of the limiting vacuolar membrane from the trans-Golgi to the lysosome. We will put our findings into context with the interaction of (iii) the COPII coat and the TRAPP I complex, which is required for ER to Golgi forward transport (recent evidence in fact calls into question the classification of TRAPP complexes as tethers, as discussed later). Table 1 lists the constituents of the coats and tethers mentioned, and some of their properties and interaction partners.

\section{TIMING AND FACTORS OF VESICLE COAT REMOVAL}

The uncoating of vesicles is initiated during or shortly after scission of the newly formed vesicles, either by the recruitment of uncoating factors or by inactivating GTPases that control the coat formation. Clearly, the presence of a complete coat would prevent the SNARE-mediated fusion of the vesicles with the target membrane. It is thus crucial to examine what is known about the uncoating processes in transport steps, and how this may interplay in a timely manner with a possible recognition of the vesicle through its coat.

The removal of coat elements is best studied for clathrin, where the disassembly of the triskelia is catalyzed by the ATPase Hsp70. The uncoating enzyme is recruited to the vesicle by a co-chaperone with binding sites for clathrin and Hsp70, either neuronal auxilin 1 or the ubiquitously expressed GAK/auxilin 2 (Ungewickell et al., 1995; Greener et al., 2000). In clathrincoated endocytic AP-2 vesicles, where adaptor proteins (AP-2) and cargo can be analyzed by TIRF (total internal reflection fluorescence) microscopy, the removal of the clathrin cage and the adaptor layer may happen independently (Rappoport et al., 2006). A large part of the clathrin disappears from vesicles shortly after scission, before the vesicles move away from the plasma membrane (Massol et al., 2006; Mattheyses et al., 2011). Auxilin is recruited in a burst, shortly before the coat formation is complete (Massol et al., 2006). This observation could point toward a simple stochastically driven loss of the coat. An alternative interpretation, however, is that the observed heterogeneity of the kinetics is due to different populations of clathrin-coated vesicles. Differences in the persistence of the coat may reflect differences in cargo and in the sites to which the vesicles are headed.

AP-1 and AP-3 dependent intracellular transport is more difficult to analyze. Three-dimensional time-lapse movies had to be recorded for AP-1 and AP-3 vesicles, and their lifetime is comparable to that of AP-2 vesicles (Kural et al., 2012). The apparently heterogeneous disassembly behavior of the clathrin cage makes it rather unlikely that clathrin is typically involved in vesicle recognition through tethers at the target membrane. Currently, no evidence exists that the clathrin cage is recognized by tethers or used for recognition at the target membrane, even though this is not a conclusive argument to rule out such a function. The adaptor complexes on the other hand are candidates for coat/tether interactions; and indeed one example of such an interaction has been reported, as discussed later.

Initial evidence for an early removal of the COP coats came from the analysis of factors that stimulate the activity of small GTPases required for coat and vesicle formation. The stimulation of their low intrinsic GTPase activity inactivates them and induces their release from the membrane (Pucadyil and Schmid, 2009). In the case of the COPII coat, this activation is achieved by the fully assembled coat itself, where components of the inner and the outer layer of the coat act synergistically on the small GTPase Sarlp (Antonny et al., 1997). In contrast, the GTPase Arflp that is required for COPI coat assembly is activated by proteins that can sense the curvature of the vesicle 


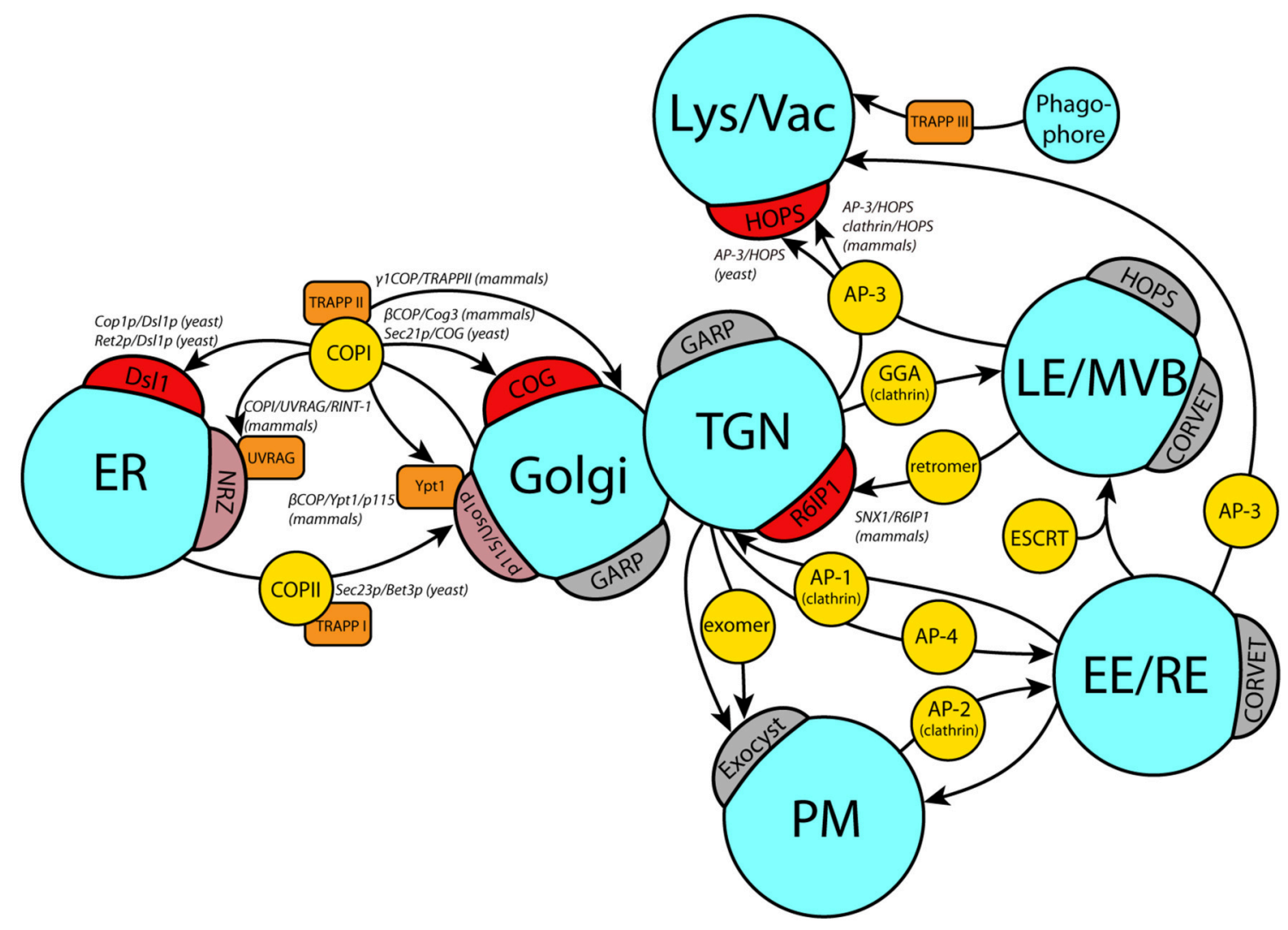

FIGURE 1 | Coat/tether interactions at different target organelles. Schematic overview of currently known coat/tether interactions on their respective organelles. Arrows indicate the transport pathway with the involved coats in yellow circles. Direct interactions of coats with tethers on the target membranes (crescents) are marked in red, or light red if they require additional factors (orange boxes). Where known, the precise subunits involved in the coat/tether interaction are listed in italic writing in the order coat subunit/tether subunit. A few selected tethers with no known coat interactions on the respective membrane are depicted in gray crescents. ER, endoplasmic reticulum; TGN, trans Golgi network; Lys/Nac, lysosome/vacuole; LE/MVB, late endosome/multivesicular body; EE, early endosome; RE, recycling endosome; PM, plasma membrane.

membrane (Antonny et al., 2001). Both findings, however, were interpreted in a way that COPI and COPII vesicles lose their coat quite early after fission. However, more recent findings suggest that these results may not fully reflect the physiologically occurring processes. Mutations in subunits of the Dsl1 complex or the HOPS complex as well as mutations in the corresponding SNAREs led to the accumulation of large amounts of coated vesicles (Angers and Merz, 2009; Zink et al., 2009), suggesting that the tethering complexes are involved in uncoating. In addition, $\mathrm{CHO}$ cells depleted of a COG subunit accumulate COPI-coated vesicles (Zolov and Lupashin, 2005). These results indicate that vesicles still carry their coat when they arrive at the target membrane, and that coat/tether interactions are possible in vivo. The recently determined structure of the COPI coat revealed that the building blocks of the coat, the triads, are connected by those domains that are the binding sites for Dsl1p of the Dsl1 tethering complex. The $\mu$-domain of $\delta$-COP at some linkages, or $\varepsilon$-COP and the C-terminus of $\alpha$-COP at others (Andag and Schmitt, 2003; Zink et al., 2009; Hsia and Hoelz, 2010; Dodonova et al., 2015; Suckling et al., 2015). This indicates that the Dsl1 complex may be involved in the removal of triads from the vesicle, possibly by competitively binding COPI complexes at these connection sites thus disassembling the coat units. Further proof for this is required since uncoating could not be reconstituted in vitro so far. Interestingly though, these findings suggest that the timed coat removal of COPI vesicles differs from that of clathrin coats, at least in yeast: The coat of COPI vesicles appears to be released only after vesicle recognition on the target membrane.

Comparable COPII clusters were only observed in COPII budding mutants, and not in mutants with fusion defects (Shindiapina and Barlowe, 2010). More precisely, the mutation of the COPI tether Usolp did not lead to accumulation of coated COPII vesicles. However, independent evidence indicates that COPII vesicles may remain partially coated: COPII vesicles that are formed by permeabilized NRK cells carry more than $55 \%$ of the inner COPII shell and $15 \%$ of the outer COPII shell (Cai et al., 2007; Bentley et al., 2010). Vesicles produced in vitro by permeabilized yeast cells also retain most of their coat, as determined for subunits from the inner and outer shell (Lord et al., 2011). The results support the hypothesis that coats or partially present coats on vesicles may be used for identification at the target membrane (Trahey and Hay, 2010). 
TABLE 1 | Composition and properties of coats and tethers involved in transport between ER and Golgi and from the late Golgi to the lysosome in yeast.

\begin{tabular}{|c|c|c|c|}
\hline & COPI / Dsl1 & COPII / TRAPP I & AP-3 / HOPS \\
\hline $\begin{array}{l}\text { Acronym stands } \\
\text { for: }\end{array}$ & $\begin{array}{l}\text { COPI (coat protein complex I) } \\
\text { Dsl1 (dependent on Sly1-20) }\end{array}$ & $\begin{array}{l}\text { COPII (coat protein complex II) } \\
\text { TRAPP (transport protein particle) }\end{array}$ & $\begin{array}{l}\text { AP-3 (adaptor protein complex } 3 \text { ) } \\
\text { HOPS (homotypic fusion and vacuole } \\
\text { protein sorting }\end{array}$ \\
\hline Transport step & Golgi-ER & ER-Golgi & Golgi-lysosome \\
\hline Coat proteins & $\alpha^{-}, \beta-, \beta^{\prime}, \gamma^{-}, \delta^{-}, \varepsilon^{-}, \zeta^{-C O P}$ & Sec23p, Sec24p, Sec13p, Sec31p & Apl5p, Apl6p, Apm3p, Aps3p \\
\hline $\begin{array}{l}\text { Subunits of the } \\
\text { tethering complex }\end{array}$ & Dsl1p, Dsl3(Sec39)p, Tip20p & $\begin{array}{l}\text { Bet3p, Bet5p, Trs20p, Trs23p, Trs31p, } \\
\text { Trs33p }\end{array}$ & $\begin{array}{l}\text { Vps39p, Vps41p, } \\
\text { Vps11p, Vps16p, Vps18p, Vps33p }\end{array}$ \\
\hline SNARES & $\begin{array}{l}\text { R-SNARE Sec22p } \\
\text { Qa-SNARE Ufe1p } \\
\text { Qb-SNARE Sec20p } \\
\text { Qc-SNARE Use1p }\end{array}$ & $\begin{array}{l}\text { R-SNARE Sec22p } \\
\text { Qa-SNARE Sed5p } \\
\text { Qb-SNARE Bos1p } \\
\text { Qc-SNARE Bet1p }\end{array}$ & $\begin{array}{l}\text { R-SNARE Ykt6p } \\
\text { Qa-SNARE Vam3p } \\
\text { Qb-SNARE Vti1p } \\
\text { Qc-SNARE Vam7p }\end{array}$ \\
\hline Type of MTC & $\begin{array}{l}\text { Member of the CATCHR family (complexes } \\
\text { associated with tethering containing helical } \\
\text { rods) including the COG, GARP and exocyst } \\
\text { complexes }\end{array}$ & $\begin{array}{l}\text { TRAPP I shares five subunits with the TRAPP II } \\
\text { and III complexes which are required for } \\
\text { intra-Golgi transport and autophagosome } \\
\text { biosynthesis }\end{array}$ & $\begin{array}{l}\text { The HOPS complex is a Class C Vps } \\
\text { complex. It shares four subunits } \\
\text { Vps11-33) with the endosomal CORVET } \\
\text { complex: Unique CORVAT subunits are } \\
\text { Vps3p and Vps8p }\end{array}$ \\
\hline $\begin{array}{l}\text { Main structural } \\
\text { elements }\end{array}$ & $\begin{array}{l}\alpha \text {-helical bundles or "CATCHR domains" } \\
\text { (Dsl1p, Tip20p), } \\
18 \text { nm long } \alpha \text {-solenoid DsI3(Sec39)p }\end{array}$ & $\begin{array}{l}\text { Small globular subunits, three of them are longin } \\
\text { domains }\end{array}$ & $\begin{array}{l}\text { Five subunits consist of } \beta \text {-propellers } \\
\text { followed by an } \alpha \text {-solenoid, } \\
\text { Vps33p is an SM protein }\end{array}$ \\
\hline $\begin{array}{l}\text { Conformational } \\
\text { changes }\end{array}$ & $\begin{array}{l}\text { Can switch between an Y-shaped and an } \\
\text { closed conformation }\end{array}$ & No change in size and shape & Size can vary between 28 to $40 \mathrm{~nm}$ \\
\hline Size & $\begin{array}{l}20 \mathrm{~nm} \text { long rod in its closed conformation } \\
250 \mathrm{kDa}\end{array}$ & $\begin{array}{l}18 \times 6.5 \times 5 \mathrm{~nm} \\
170 \mathrm{kDa}\end{array}$ & $650 \mathrm{kDa}$ \\
\hline $\begin{array}{l}\text { Biochemical } \\
\text { activities }\end{array}$ & & $\begin{array}{l}\text { Bet3p, Bet5p, Trs23p, plus Trs31p act as GEF } \\
\text { for Ypt1p/Rab1 }\end{array}$ & $\begin{array}{l}\text { Yps41p is an effector of the Ypt/Rab } \\
\text { GTPase Ypt7p }\end{array}$ \\
\hline Kinases involved & & Hrr25p & Yck3p \\
\hline Recruitment to & ER & COPII vesicle & Lysosome or multivesicular body \\
\hline
\end{tabular}

\section{TETHERING COMPLEXES COAT THE TARGET MEMBRANE}

The next question concerns the localization of the tethering complexes. If the tethering indeed involves their interaction with the vesicle coat, then the tethering complexes should either be localized at the target membrane, or they must be recruited to it during the tethering process.

The Dsl1 complex and its mammalian counterpart, the syntaxin 18 or NRZ complex (Aoki et al., 2009; Civril et al., 2010), are in a very tight complex with the ER-localized SNAREs, and visualization of their constituents gave a pattern consistent with an ER localization (Figure 2A; Reilly et al., 2001; Hirose et al., 2004; Arasaki et al., 2006; Aoki et al., 2009; Meiringer et al., 2011). For additional details on the more complex functional aspects of the mammalian ZW10 complex, see Schmitt (2010).

Similarly, the HOPS complex localizes to the target membrane of AP-3 vesicles, the lysosome, but also to late endosomes or multivesicular bodies (MVB) (Nakamura et al., 1997; Cabrera et al., 2010). This reflects the fact that the HOPS is involved in different transport steps: (i) homotypic lysosome/lysosome fusion, (ii) late endosome (MVB)/lysosome fusion and (iii) the fusion of AP-3 coated vesicles with the lysosome (Bowers and Stevens, 2005). This begs the question how the specific localization of tethers is determined.

\section{RECRUITMENT FACTORS OF TETHERS (1): SNARES}

None of the tethers discussed here has subunits that carry a transmembrane domain. In fact, only a few homodimeric coiledcoil Golgi tethers like giantin are integral membrane proteins (Gillingham and Munro, 2003). Therefore, the sites that the Dsl1, HOPS, and TRAPP complexes are recruited to are determined by additional factors on the surface of the membranes. Here, a very interesting interaction comes into play: Both the Dsl1 and the HOPS complex were shown to bind single SNAREs via $\mathrm{N}$-terminal domains that lie in front of the SNARE domains.

In case of the Dsl1 complex, these are the $\mathrm{N}$-terminal domains of the $\mathrm{Q}_{\mathrm{b}}$-SNARE Sec20p and the $\mathrm{Q}_{\mathrm{c}}$-SNARE Uselp (Ren et al., 2009; Diefenbacher et al., 2011; Meiringer et al., 2011). Both domains do not show any sequence similarities to other $\mathrm{N}$ terminal domains of SNARE proteins and were not predicted to contain either a lipid binding domain, a longin or $\mathrm{H}_{\mathrm{abc}} \alpha$ helical domain. Surprisingly, the formation of only one of these two connections is still sufficient for cell viability (Kraynack et al., 2005; Tripathi et al., 2009). Ren et al. (2009) also observed binding to the fully assembled SNARE complex, while Meiringer et al. (2011) observed very inefficient binding of the full set of SNAREs to the Dsl1 complex in vitro. Instead, they found that the lipid-anchored R-SNARE Ykt6p may act as an acceptor for Sec22p, the R-SNARE that associates with the Q-SNAREs at the ER. 


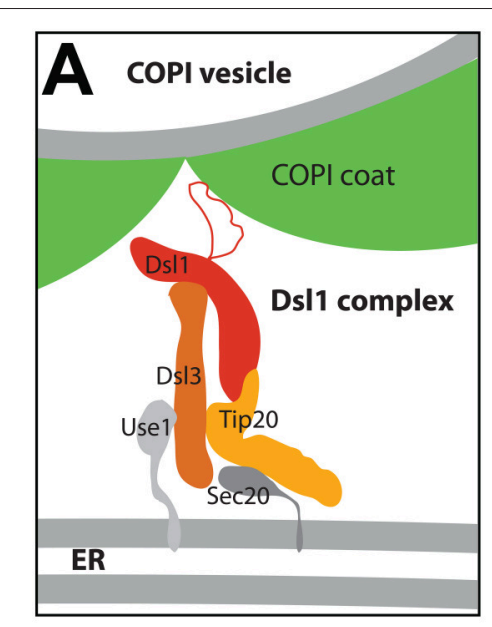

coat/tether interaction

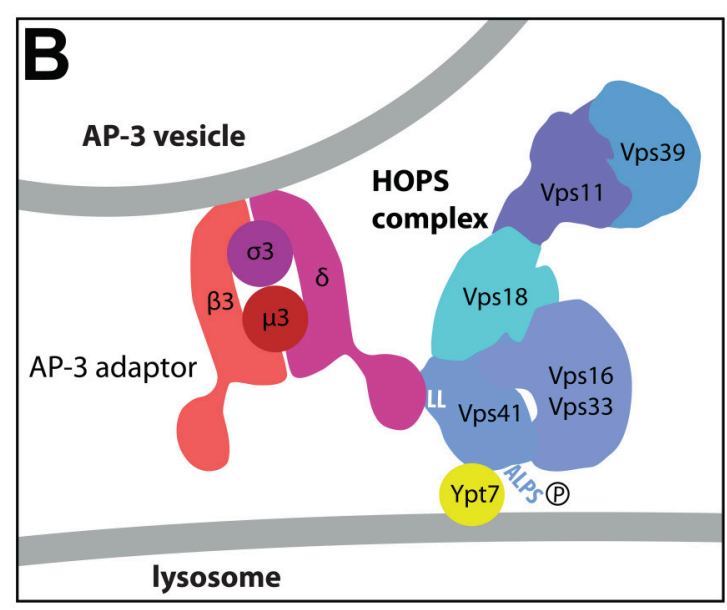

coat/tether interaction

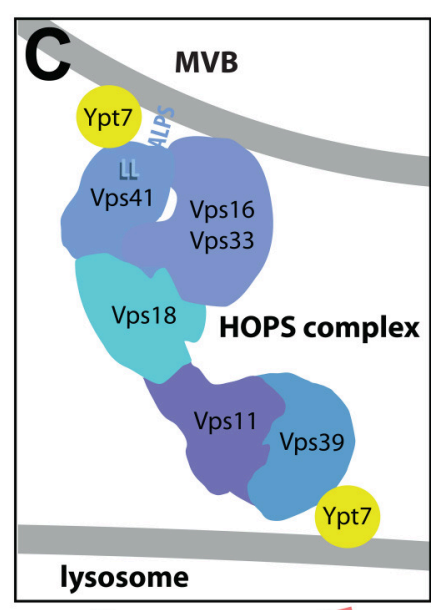

coat/tether interaction

FIGURE 2 | Models for the interaction of the Dsl1 and HOPS complexes with COPI or AP-3 coats. (A) The structure of the Dsl tethering according to the structures determined by the Hughson lab (Ren et al., 2009; Tripathi et al., 2009). Dsl1p binds COPI coat via an unstructured lasso domain (Andag and Schmitt, 2003; Ren et al., 2009; Schmitt, 2010; Suckling et al., 2015) at the sites where the coat triads connect (Dodonova et al., 2015). They may represent the sites where coat depolymerization begins. (B,C) Two different tethering modes of the HOPS complex at the surface of the lysosome (Cabrera et al., 2010). The arrangement of subunits as shown here was determined by negative stain EM of different HOPS constructs (Kuhlee et al., 2015). (C) Depicts the HOPS complex as a tether bridging two membranes very much like in homotypic lysosome-lysosome fusion. At the surface of the multivesicular body, however, the Vps41 subunit can bind to the curved membrane via its curvature-sensing ALPS domain. In this conformation, the binding site for the $\delta$-subunit of the AP-3 complex is masked (C). At the surface of the flat lysosome, in contrast, the ALPS domain cannot bind efficiently to the membrane, (i) due to lower curvature of the membrane and, (ii), since the ALPS motif is phosphorylated by the Yck3 kinase (B). For the interaction with the membrane, HOPS has to rely solely on the interaction of Vps41p with GTP-bound Ypt7p and on the ability of other HOPS subunits to bind to acidic lipids (not illustrated here; Behrmann et al., 2014; Orr et al., 2015). Importantly, in this configuration the $\delta$-subunit of the AP-3 complex has access to its binding site at the Vps41p subunit, a double leucine motif marked as LL in this Figure. By using this specific binding mode, Golgi-derived AP-3 coated vesicles preferentially bind to HOPS complexes at the surface of the lysosome thereby avoiding fusion with endosomes.

The Sly1 proteins may act as additional potential recruiting factors for the Dsl1/NRZ complexes. They are members of the Sec1/Munc18-like protein family (SM), which cooperate with SNAREs during vesicle fusion. The Slyl proteins act in transport between ER and Golgi, and there is evidence that Slylp is required for retrograde transport (Reilly et al., 2001; VanRheenen et al., 2001; Li et al., 2005). It associates with the tethering complex in yeast and mammalian cells to varying degrees. It may do so indirectly through its interaction with the SNAREs (Hirose et al., 2004; Kraynack et al., 2005; Li et al., 2005).

The HOPS complex also binds to individual SNARE proteins, and contains a stably associated SNARE interacting SM protein (Seals et al., 2000). It binds the $\mathrm{Q}_{\mathrm{a}}$-SNARE Vam3p via its $\mathrm{N}$ terminal $\mathrm{H}_{\mathrm{abc}}$-domain, and the $\mathrm{Q}_{\mathrm{c}}$-SNARE Vam7p via the PX lipid-binding domain (Krämer and Ungermann, 2011; Lobingier and Merz, 2012; Lürick et al., 2015). In addition, the HOPS complex can interact with partially or fully assembled bundles of the SNARE domains (Baker et al., 2015; Lürick et al., 2015). This interaction is mediated by the stable HOPS subunit Vps33p, a member of the Sec1/Munc18 protein (SM) family. Vps33p, unlike other SM proteins like Vps45 and Munc18, is not able to recognize the $\mathrm{N}$-terminal peptide or the $\mathrm{H}_{\mathrm{abc}}$ domain of Vam3p on its own, and requires Vps16p in addition to fulfill this task (Lürick et al., 2015). The same subunit plus Vps18p is involved in binding of the PX-domain of Vam7p (Krämer and Ungermann, 2011).
In summary, both the Dsl1 and the HOPS complexes are able to bind to individual SNAREs as well as assembled SNARE complexes (Ren et al., 2009; Krämer and Ungermann, 2011; Lobingier and Merz, 2012; Baker et al., 2015). This suggests that their function lasts across the SNARE zippering process, possibly by acting as SNARE complex assembly factors (Baker et al., 2015).

As mentioned above, SNAREs are promiscuous, so additional recruiting factors are needed. In fact, the tethering complex/SNARE interactions may not be essential for the actual tethering step (Hickey and Wickner, 2010), since the HOPS complex can rely on GTPase or direct binding to lipids for the docking of membranes, as discussed in the next paragraph.

\section{RECRUITMENT FACTORS OF TETHERS (2): SMALL GTPases AND LIPIDS}

Another class of proteins that are both key to membrane identity and act as recruiting factors for tethering complexes are the small GTPases of the Ypt/Rab family. For the Dsl1 complex-dependent retrograde transport, the Spang lab has used a YPT1 (Rab1) knock-out strain to show that this GTPase is not only required for forward transport, but is also involved in Golgi-ER retrograde transport in yeast (Kamena 
et al., 2008). Mammalian cells express a much larger set of Ypt/Rab GTPases, and the retrograde transport is regulated by a specialized small GTPase Rab18. Evidence for an involvement of Rab/Ypt GTPase in the tethering process of COPI vesicles in mammalian cells was presented recently by Gillingham et al. (2014) who identified the Dsl1/NRZ complex as an effector of Rab18.

For the HOPS complex-dependent tethering to vacuolar membranes, the small Ypt/Rab GTPase Ypt7p was shown to be more important than the interaction of HOPS with SNAREs (Hickey et al., 2009; Hickey and Wickner, 2010). In fact, the HOPS complex is an effector of Ypt7p, since it preferentially binds to the GTP-bound form of this small GTPase (Price et al., 2000) In addition, the HOPS complex can bind to the membrane directly via the head groups of phosphoinositides and other acidic lipids (Stroupe et al., 2006; Behrmann et al., 2014; Orr et al., 2015).

The HOPS complex seems to be ideally suited as a tether since it carries two different Ypt7-binding subunits, Vps39p and Vps41p (also known as Vam6p and Vam2p; Price et al., 2000; Brett et al., 2008). Both are positioned at the opposing ends of its elongated structure (Bröcker et al., 2012). Thus, the HOPS complex can form a bridge between late endosomes or multivesicular bodies (MVBs) on one side and the lysosome on the other side by interacting with Ypt7 GTPases on the opposing membranes (Ho and Stroupe, 2015). Besides this twoarmed tethering mode, the lysosome-localized HOPS complex can also act as a receptor for AP-3 vesicles via Apl5p, the $\delta$ adaptin-like subunit of the AP-3 coat (Rehling et al., 1999; Angers and Merz, 2009; Figure 2B). This tethering mode requires the presence of Ypt7p only on the target membrane. Transport via the AP-3-coated vesicles is involved in a special transport route between Golgi and lysosome, by which yeast cells avoid fusion of vesicles carrying lysosome-bound membrane proteins with multivesicular bodies. In yeast, this is achieved by direct vesicular transport from the Golgi to the lysosome via AP-3 vesicles. A typical cargo for this step is the enzyme alkaline phosphatase (ALP, Pho8p). Some other cargo proteins are themselves part of the targeting machinery, like the SNAREs Vam3p and Nyv1p and the lipid-anchored Type I casein kinase Yck3p (Cowles et al., 1997; Ostrowicz et al., 2008). The AP-3 transport route prevents these proteins from being internalized by the MVBs or from becoming active at the surface of endosomes.

How can the HOPS complex switch between the different tethering modes? One obvious possibility is through posttranslational modifications. The phosphorylation of the HOPS complex changes the dependence of HOPS on Ypt7-GTP for its tethering function (Brett et al., 2008; Cabrera et al., 2009; Ho and Stroupe, 2015). Recent in vitro experiments with liposomes clearly showed that the phosphorylated HOPS requires Ypt7-GTP for tethering, while non-phosphorylated HOPS complex is active if Ypt7-GDP is present on both membranes (Zick and Wickner, 2012; Ho and Stroupe, 2015). This antagonistic relationship between phosphorylation and the GTP/GDP status suggests that the phosphorylation adjusts the balance between the different membrane recruitment modes for HOPS.

Significantly, the enzyme that phosphorylates the HOPS complex was mentioned above already as cargo of the AP-3 pathway. This membrane-anchored kinase, Yck3p, depends on this transport route for its proper localization to the lysosome (Sun et al., 2004; LaGrassa and Ungermann, 2005). At the same time, Yck3p was shown to be as equally required for proper functioning of the AP-3 pathway as the subunits of the AP-3 coat (Anand et al., 2009; Cabrera et al., 2009). A clue as to how Yck3p can mechanistically bring about the switch in tethering modes of the HOPS complex came when Christian Ungermann's lab identified the phosphorylation sites and the AP-3 binding site within HOPS. Both are located in the N-terminal part of the Ypt7p-interacting subunit Vps41p (Cabrera et al., 2009, 2010). The binding site for the AP-3 subunit Apl5p lies in front of the putative $\beta$-propeller domain (Cabrera et al., 2010), while the phosphosites lie within an $\alpha$-helical region that is adjacent to the opposite end the putative $\beta$-propeller (Cabrera et al., 2009). This means that the phosphosites and the Apl5p-binding site come close to each other in the Vps41 protein and thus may affect each other directly (The same region is also involved in the binding of Ypt7p).

The $\alpha$-helical region was predicted to constitute a so-called ArfGAP1 lipid packing sensor or amphipathic lipid packing sensor (ALPS) motif (Drin et al., 2007). Phosphomimetic mutations in this domain prevent membrane binding in vivo and in vitro (Cabrera et al., 2009, 2010). The binding to small liposomes is also prevented when Vps41p is pre-incubated with Apl5p (Cabrera et al., 2010). Thus, the N-terminus of Vps41p can adopt two conformations, one in which Vps41p binds to the membrane directly (without the help of Ypt7p) and does not allow binding of the AP- 3 coat. In the second conformation, phosphorylation of the ALPS motif prevents binding to the membrane and exposes the AP-3 binding site. Two factors favor the transition on the first conformation to the second: the low curvature of the lysosomal membrane and the presence of the Yck3p on the surface of the lysosome. According to the model proposed by Cabrera et al. (2010), transition between these two states occurs after the recruitment of endosomes/MVBs to the lysosome. Since the endosomes/MVBs have a diameter of $100 \mathrm{~nm}$ (Luhtala and Odorizzi, 2004; Balderhaar and Ungermann, 2013), the membrane curvature is low and Yps41p can bind directly to it, while the AP-3 binding site is masked (Figure 2C). After fusion with the lysosome, Vps41p loses its contact with the flat lysosomal membrane, the ALPS motif can be phosphorylated, thereby lowering the affinity of the ALPS domain for membranes even more. As a consequence, the binding site for the AP-3 complex becomes accessible. This ensures that the coat/tether interaction occurs only at the surface of the lysosome. Thus, the yeast cells use a sophisticated mechanism to prevent AP-3 vesicles from fusing with MVBs. They turn a two-armed tether, which links the membranes of MVB and lysosome, to a monovalent tether that uses a coat complex as additional linker to the second membrane. 


\section{CONSERVATION OF COAT/TETHER INTERACTIONS BETWEEN YEAST AND MAMMALIAN CELLS}

The interaction between COPI and Dsllp was first described in 2001 in Saccharomyces cerevisiae (Andag et al., 2001; Reilly et al., 2001). An unstructured domain within the largest subunit of the Dsl1 complex, Dsllp itself, is required for the binding to the COPI coat (Andag and Schmitt, 2003; Ren et al., 2009). This socalled lasso domain is exposed at the tip of the whole complex approximately $20 \mathrm{~nm}$ above the membrane surface (Ren et al., 2009 ) and binds to $\delta$-COP and $\alpha$-COP via tryptophan-containing binding motifs (Andag and Schmitt, 2003). The structure of a $\delta$-COP fragment in complex with such a $\mathrm{W} \times \mathrm{W}$ motif was recently determined by Suckling et al. (2015). Another subunit of the Dsl1 complex, Tip20p, may also contribute to COPI binding (Diefenbacher et al., 2011). Curiously, all homologs of Dsl1p from aquatic fungi, from plants and metazoans are lacking the lasso domain (Hirose et al., 2004; Schmitt, 2010). Instead, in mammalian cells an additional protein called UVRAG is required for the interaction of the COPI coat with the NRZ complex (He et al., 2013). UVRAG was hitherto known for its role in endosomal transport and autophagy as part of the Vps34 phosphatidylinositol 3-kinase complex II. According to the new data, it is able to bind phosphoinositides, and it can bind to RINT-1, the mammalian homolog of Tip20p, to perform an additional role in Golgi-ER transport (He et al., 2013). The UVRAG homolog in yeast, Vps38p, is involved vacuolar protein sorting, and it has not been found to act at the ER or to be involved in autophagy (Kihara et al., 2001). Thus, the mechanism of COPI/ER tether interaction differs between yeast and mammalian cells, but it is found, in variation, across species boundaries.

The binding of AP-3 vesicles to the Vps41p HOPS subunit was discovered by Rehling et al. (1999). Angers and Merz later showed that the whole HOPS tethering complex, and not just the Vps41p subunit alone, is involved in the interaction (Angers and Merz, 2009). In metazoans, the phenotypes of AP-3 and HOPS mutants are quite similar, indicating that the proteins act in a similar pathway (Zlatic et al., 2011a). There are, however, several discrepancies: (i) Unlike those from mammalian cells, AP-3 vesicles in yeast do not carry an outer cage layer consisting of clathrin. (ii) The units from mammalian HOPS are found to associate with AP-3 adaptor proteins as well as clathrin subunits (Zlatic et al., 2011b). (iii) AP-3 vesicles in yeast and mammalian cells are destined for the lysosome. They form, however, at different organelles, the late Golgi in yeast and a tubular early endosome in mammalian cells (Dell'Angelica, 2009). (iv) In mammalian cells, the HOPS complex is recruited to sites of AP-3 vesicle formation, while in yeast it is recruited to the target membrane of the AP-3 vesicles, the lysosome as well as the late endosomes. (v) Most relevant for the context of this review is that Vps41 from metazoans lacks the motif for AP3 binding and the ALPS domain for lipid binding (Cabrera et al., 2010). However, a direct TGN to late endosome transport route for lysosomal proteins was recently described that does not require clathrin or the AP-1 adaptor complex. The vesicles that mediate this transport carry hVps41 and the SNARE VAMP7 (Pols et al., 2013). This shows a considerable diversification in HOPS complex recruitment, but nevertheless its tethering function appears to have remained conserved.

\section{TETHERS AND COATS SHARE STRUCTURAL MOTIFS}

The last paragraphs have focused on functional interactions between coats and tethers, and have found an, if not ubiquitous, but notable range of interactions. Intriguingly, not only the interactions found in several transport routes speak for an interconnection between coats and tethers. Additionally, recently solved protein structures have revealed a surprising correspondence in structural motifs between coats and tethers. The protocoatomer architecture, an $\mathrm{N}$-terminal 7-bladed $\beta$ propeller followed by extended $\alpha$-solenoids or $\alpha$-zigzag linker, is found in many subunits of coat complexes (i.e., clathrin, Sec13p, Sec31p, $\alpha$-COP and $\beta^{\prime}$-COP) as well as in nuclear porins (ter Haar et al., 1998; Fath et al., 2007; Lee and Goldberg, 2010). This $\beta$ - $\alpha$-fold architecture seems to be common to proteins that can bend membranes (Devos et al., 2006). Remarkably, the $\beta$ - $\alpha$ fold motif was also predicted for subunits of some multisubunit tethering complexes, for most of the HOPS subunits (including Vps3p and Vps8p from the related CORVET complex) and the NAG subunit of the mammalian Dsl1/NRZ complex (Nickerson et al., 2009; Civril et al., 2010; Figure 3). Experimental proof for its occurrence in tethers was obtained for the Vps18 subunit of the HOPS complex (Behrmann et al., 2014).

The $\beta$-propellers of clathrin heavy chains and of COPI subunits are oriented toward the membrane (Kirchhausen and Harrison, 1984; Dodonova et al., 2015). Similarly, the $\beta$ propellers of the HOPS subunits Vps41p and Vps18p were shown to bind to lipids (Cabrera et al., 2010; Behrmann et al., 2014). In the Dsl1 complex of yeast the Dsl3/Sec39 protein, a long a-solenoid, is also oriented with its $\mathrm{N}$-terminus towards the membrane (Ren et al., 2009). This would also position the $\beta$-propeller present in the mammalian Dsl3/Sec39 homolog NAG (neuroblastoma amplified gene) close to the membrane (Civril et al., 2010). Since NAG shares all structural elements with another protein, ROD, that acts together with ZW10 and a third component in the recruitment of microtubules to the kinetochore, the $\beta-\alpha$ architecture must be an ancient property of the Dsl3/NAG proteins (Civril et al., 2010; Schmitt, 2010). Fungi very likely lost the $\beta$-propeller encoding region from the corresponding gene (Schmitt, 2010).

Recently, an additional similarity between COPI and HOPS/CORVET subunits was noted. At the C-termini of Vps11p, Vps18p, Vps8p,Vps39p, mammalian Vps41p and $\alpha$-COP from many different species, $\mathrm{Zn}^{2+}$-binding RING domains were detected (Nickerson et al., 2009; Balderhaar and Ungermann, 2013; Kaur and Subramanian, 2015). For Vps11p, Vps18p, Vps8p, and $\alpha$-COP the importance of this domain has been proven (Eugster et al., 2000; Nickerson et al., 2009; Zink et al., 2009). 


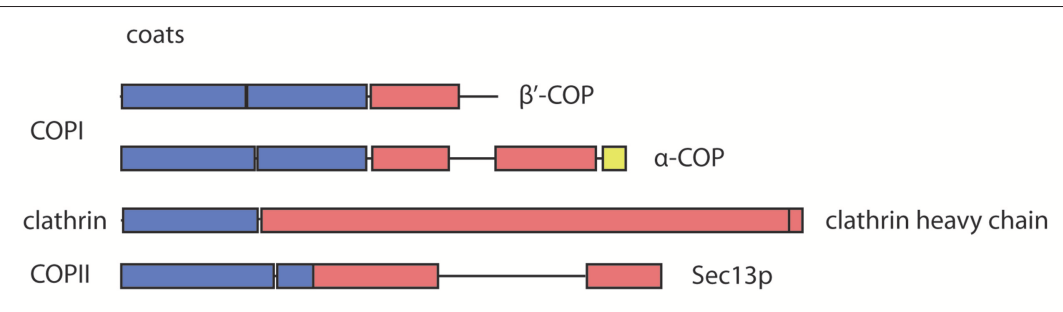

tethering complexes

NRZ/

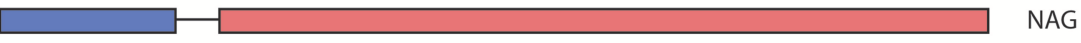

Dsl1

Dsl3/Sec39p

HOPS

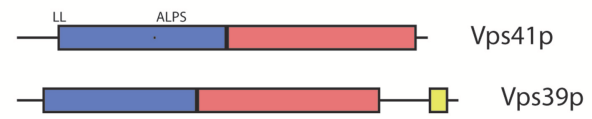

FIGURE 3 | Predicted and observed arrangement of structural protocoatomer elements in subunits of coat and tethering complexes. The protocoatomer was identified as a potentially membrane-curving protein module in proteins of the nuclear pore complex and coat complexes (Devos et al., 2006). Blue color indicates $\beta$-propellers or WD40 repeats, while $\alpha$-solenoids are indicated by red color. RING like domains (yellow) were found near the C-termini of $\alpha$-COP and several subunits of the HOPS and CORVET complexes (Vps39p as shown above and in Vps8p, Vps11p and Vps18p; Nickerson et al., 2009; Kaur and Subramanian, 2015). According to the protocoatomer theory, the $\beta-\alpha$ arrangement indicates a common evolutionary origin of coat complexes. Its occurrence in tethering complexes may indicate that they also share a common origin with subunits of the coat and nuclear pore complexes. The domain organization of coat complexes was deduced from the structural data (Fath et al., 2007; Lee and Goldberg, 2010). For NAG, the boundaries of the domains were depicted as determined by Civril et al. (2010). The Dsl3/Sec39 protein is positioned below its mammalian homolog NAG (neuroblastoma amplified gene) in a region where both share some sequence similarities. The diagrams illustrating the domain organization and specific binding sites of the HOPS subunits were depicted as proposed by Nickerson et al. (2009). ALPS, amphiphilic lipid-packing sensor; RING, Really Interesting New Gene; WD40, 40 residue long repeat that ends with a tryptophan-aspartic acid motif; NAG, neuroblastoma amplified gene.

These common features between coat proteins and tethers make the hypothesis conceivable that the coats and tethers were more alike in an ancient eukaryote, where both formed a proteinaceous layer at the surface of intracellular membranes. From that, they diversified and developed either to the cageforming proteins around the vesicle, or a layer of vesiclecapturing proteins at the target membrane.

\section{TRAPP I/COPII INTERACTIONS}

One of the best characterized coat/tether interactions is that between the TRAPP I complex and COPII coat ( $\mathrm{Yu}$ et al., 2006; Cai et al., 2007). The ability to bind vesicle coats and its apparent steady-state Golgi localization suggested that the TRAPP I complex acts as a COPII vesicle tether (Kim et al., 2006). Recently, evidence has accumulated that the complex acts upstream of tethering.

In general, the TRAPP 1 complex shows a quite distinct behavior and structural features compared to the Dsl1 and HOPS complexes: (i) TRAPP I is recruited to free COPII vesicles (Cai et al., 2007). It appears Golgi-localized at steady state since COPII vesicles fuse with their target membrane very quickly (Wang J. et al., 2015). (ii) There is no direct evidence for an interaction between the TRAPP I complex and SNAREs, even though many genetic interactions of a bet3 mutation with SNARE-encoding genes have been described (Sacher et al., 2000). (iii) The TRAPP I complex is an activator (GEF) of the ER-Golgi-specific Rab/Ypt-GTPase Yptlp (Jones et al., 2000; Wang et al., 2000), rather than a GTPase effector like for instance Vps41p of the HOPS complex. Accordingly, the TRAPP I complex does not need Ypt1p for its recruitment to vesicles.

The following observations indicate that the TRAPP I complex acts before the actual tethering step. The TRAPP I subunit Bet $3 p$ binds to the same site at the COPII subunit Sec23p that is also the binding site for Sarlp, the GTPase that triggers coat formation (Cai et al., 2007; Lord et al., 2011). Notably, Bet3p and Sar1p are later displaced by the casein kinase Hrr25p (Lord et al., 2011). This kinase is activated by Yptlp on the vesicles (Wang J. et al., 2015), and phosphorylation of Sec23p and Sec24p by Hrr25p is required though not sufficient for uncoating (Lord et al., 2011). The phosphorylation state of Sec23p determines whether the coat subunit is ready for vesicle fusion or vesicle formation (Murakami et al., 1999; Dudognon et al., 2004; Lord et al., 2011; Bhandari et al., 2013). Taken together, these findings suggests that the TRAPP I binding represents an intermediate step of vesicle maturation that occurs well before the actual tethering step, and that the complex is released before COPII vesicles reach the Golgi membrane. The function of the TRAPP 1 complex rather appears to lie in determining the directionality of transport. A more likely tether for COPII vesicles is the coiledcoil homodimer tether Uso1p/p115 (Waters et al., 1992; Cao et al., 1998; Allan et al., 2000). This tether is also activated by Ypt1p/Rab1 (Allan et al., 2000), and binds to the SNAREs rbet1 and sec22b (Wang T. et al., 2015). Since Bet1p and Sec22p are present on opposing membranes in yeast (Parlati et al., 2000), Uso1p/p115 may bridge the gap between the membranes by 
interacting with single SNAREs at the vesicle and the target membrane (Grabski et al., 2012).

\section{CONCLUSIONS}

To summarize, Dsl1/NRZ and HOPS complexes are representatives of tethering complexes that interact with coats. Both contain protocoatomer-like subunits. This indicates that these two tethers could be derived from primordial coat complexes. In ancestral eukaryotic cells, both donor and acceptor membranes may have been covered by different coats and fusion may have been initiated by the direct contact between them. During evolution, one of these coats acquired and improved its capability to induce membrane curvature, while the other with preference for flat membranes developed into a tethering factor. In line with this theory, the HOPS complex can bind to flat and curved membranes in a regulated manner, but it cannot induce curvature (Cabrera et al., 2010). The Dsl1/NRZ complex, in contrast, is a mixture of protocoatomer and CATCHR subunits. Notably, those two tethering complexes that share some coat characteristics are able to bind coats. Since these interactions were not conserved in metazoans or require additional binding partners, it is not clear whether the coat/tether interactions described here represent remainders of an ancient fusion mechanism, or whether fungi simply reinvented this tethering mode. The fact that they are still

\section{REFERENCES}

Allan, B. B., Moyer, B. D., and Balch, W. E. (2000). Rabl recruitment of p115 into a cis-SNARE complex: programming budding COPII vesicles for fusion. Science 289, 444-448. doi: 10.1126/science. 289.5478.444

Anand, V. C., Daboussi, L., Lorenz, T. C., and Payne, G. S. (2009). Genomewide analysis of AP-3-dependent protein transport in yeast. Mol. Biol. Cell 20, 1592-1604. doi: 10.1091/mbc.E08-08-0819

Andag, U., Neumann, T., and Schmitt, H. D. (2001). The coatomer interacting protein Dsllp is required for Golgi-to-ER retrieval in yeast. J. Biol. Chem. 276, 39150-39160. doi: 10.1074/jbc.M105833200

Andag, U., and Schmitt, H. D. (2003). Dsllp, an essential component of the Golgi-endoplasmic reticulum retrieval system in yeast, uses the same sequence motif to interact with different subunits of the COPI vesicle coat. J. Biol. Chem. 278, 51722-51734. doi: 10.1074/jbc.M3087 40200

Angers, C. G., and Merz, A. J. (2009). HOPS interacts with Apl5 at the vacuole membrane and is required for consumption of AP-3 transport vesicles. Mol. Biol. Cell 20, 4563-4574. doi: 10.1091/mbc.E09-04-0272

Angers, C. G., and Merz, A. J. (2011). New links between vesicle coats and Rab-mediated vesicle targeting. Semin. Cell Dev. Biol. 22, 18-26. doi: 10.1016/j.semcdb.2010.07.003

Antonny, B., Huber, I., Paris, S., Chabre, M., and Cassel, D. (1997). Activation of ADP-ribosylation factor 1 GTPase-activating protein by phosphatidylcholine-derived diacylglycerols. J. Biol. Chem. 272, 30848-30851. doi: 10.1074/jbc.272.49.30848

Antonny, B., Madden, D., Hamamoto, S., Orci, L., and Schekman, R. (2001). Dynamics of the COPII coat with GTP and stable analogues. Nat. Cell Biol. 3 , 531-537. doi: 10.1038/35078500

Aoki, T., Ichimura, S., Itoh, A., Kuramoto, M., Shinkawa, T., Isobe, T., et al. (2009). Identification of the neuroblastoma-amplified gene product as a component of the syntaxin 18 complex implicated in Golgi-to-endoplasmic reticulum in operation and can be used for specific targeting purposes indicates that coat/coat contacts could indeed be considered as a part of an ancient fusion mechanism. This notion is in line with the organellar paralogy model (Dacks and Field, 2007). Coat/tether interaction can be useful in preventing premature mixing of different transport routes (Cabrera et al., 2010) or to keep membrane domains, where COPI vesicles arrive, separated from those where COPII vesicles form (Zink et al., 2009). Of course, more research has to be done to find whether other coat/tether interactions have specialized functions. At least one example exists where the p115 tether is involved in the regulation of COPI coat formation at the Golgi (Guo and Linstedt, 2013). The structure determination of other tethering factors will be extremely helpful in determining whether they too share motifs with coats.

\section{AUTHOR CONTRIBUTIONS}

All authors listed, have made substantial, direct and intellectual contribution to the work, and approved it for publication.

\section{FUNDING}

SB was supported by a stipend from the Max Planck Society and SS received an "excellent stipend" from the GGNB graduate school.

retrograde transport. Mol. Biol. Cell 20, 2639-2649. doi: 10.1091/mbc.E08-111104

Arasaki, K., Taniguchi, M., Tani, K., and Tagaya, M. (2006). RINT-1 regulates the localization and entry of ZW10 to the syntaxin 18 complex. Mol. Biol. Cell 17, 2780-2788. doi: 10.1091/mbc.E05-10-0973

Baker, R. W., Jeffrey, P. D., Zick, M., Phillips, B. P., Wickner, W. T., and Hughson, F. M. (2015). A direct role for the Sec1/Munc18-family protein Vps33 as a template for SNARE assembly. Science 349, 1111-1114. doi: $10.1126 /$ science.aac7906

Balderhaar, H. J., and Ungermann, C. (2013). CORVET and HOPS tethering complexes - coordinators of endosome and lysosome fusion. J. Cell Sci. 126, 1307-1316. doi: 10.1242/jcs.107805

Behnia, R., and Munro, S. (2005). Organelle identity and the signposts for membrane traffic. Nature 438, 597-604. doi: 10.1038/nature04397

Behrmann, H., Lurick, A., Kuhlee, A., Balderhaar, H. K., Brocker, C., Kummel, D., et al. (2014). Structural identification of the Vps18 beta-propeller reveals a critical role in the HOPS complex stability and function. J. Biol. Chem. 289, 33503-33512. doi: 10.1074/jbc.M114.602714

Bentley, M., Nycz, D. C., Joglekar, A., Fertschai, I., Malli, R., Graier, W. F., et al. (2010). Vesicular calcium regulates coat retention, fusogenicity, and size of pre-Golgi intermediates. Mol. Biol. Cell 21, 1033-1046. doi: 10.1091/mbc.E0910-0914

Bhandari, D., Zhang, J., Menon, S., Lord, C., Chen, S., Helm, J. R., et al. (2013). Sit4p/PP6 regulates ER-to-Golgi traffic by controlling the dephosphorylation of COPII coat subunits. Mol. Biol. Cell 24, 2727-2738. doi: 10.1091/mbc.E13-020114

Bowers, K., and Stevens, T. H. (2005). Protein transport from the late Golgi to the vacuole in the yeast Saccharomyces cerevisiae. Biochim. Biophys. Acta 1744, 438-454. doi: 10.1016/j.bbamcr.2005.04.004

Brandhorst, D., Zwilling, D., Rizzoli, S. O., Lippert, U., Lang, T., and Jahn, R. (2006). Homotypic fusion of early endosomes: SNAREs do not determine fusion specificity. Proc. Natl. Acad. Sci. U.S.A. 103, 2701-2706. doi: $10.1073 /$ pnas.0511138103 
Brett, C. L., Plemel, R. L., Lobingier, B. T., Vignali, M., Fields, S., and Merz, A. J. (2008). Efficient termination of vacuolar Rab GTPase signaling requires coordinated action by a GAP and a protein kinase. J. Cell Biol. 182, 1141-1151. doi: $10.1083 /$ jcb.200801001

Bröcker, C., Kuhlee, A., Gatsogiannis, C., Balderhaar, H. J., Hönscher, C., Engelbrecht-Vandre, S., et al. (2012). Molecular architecture of the multisubunit homotypic fusion and vacuole protein sorting (HOPS) tethering complex. Proc. Natl. Acad. Sci. U.S.A. 109, 1991-1996. doi: $10.1073 /$ pnas. 1117797109

Brunet, S., and Sacher, M. (2014). Are all multisubunit tethering complexes bona fide tethers? Traffic 15, 1282-1287. doi: 10.1111/tra.12200

Cabrera, M., Langemeyer, L., Mari, M., Rethmeier, R., Orban, I., Perz, A., et al. (2010). Phosphorylation of a membrane curvature-sensing motif switches function of the HOPS subunit Vps41 in membrane tethering. J. Cell Biol. 191, 845-859. doi: $10.1083 /$ jcb.201004092

Cabrera, M., Ostrowicz, C. W., Mari, M., LaGrassa, T. J., Reggiori, F., and Ungermann, C. (2009). Vps41 phosphorylation and the Rab Ypt7 control the targeting of the HOPS complex to endosome-vacuole fusion sites. Mol. Biol. Cell 20, 1937-1948. doi: 10.1091/mbc.E08-09-0943

Cai, H., Yu, S., Menon, S., Cai, Y., Lazarova, D., Fu, C., et al. (2007). TRAPPI tethers COPII vesicles by binding the coat subunit Sec23. Nature 445, 941-944. doi: 10.1038 /nature 05527

Cao, X., Ballew, N., and Barlowe, C. (1998). Initial docking of ER-derived vesicles requires Usolp and Yptlp but is independent of SNARE proteins. EMBO J. 17, 2156-2165. doi: 10.1093/emboj/17.8.2156

Civril, F., Wehenkel, A., Giorgi, F. M., Santaguida, S., Di Fonzo, A., Grigorean, G., et al. (2010). Structural analysis of the RZZ complex reveals common ancestry with multisubunit vesicle tethering machinery. Structure 18, 616-626. doi: 10.1016/j.str.2010.02.014

Cowles, C. R., Odorizzi, G., Payne, G. S., and Emr, S. D. (1997). The AP-3 adaptor complex is essential for cargo-selective transport to the yeast vacuole. Cell 91, 109-118. doi: 10.1016/S0092-8674(01)80013-1

Dacks, J. B., and Field, M. C. (2007). Evolution of the eukaryotic membranetrafficking system: origin, tempo and mode. J. Cell Sci. 120, 2977-2985. doi: $10.1242 /$ jcs. 013250

Dell'Angelica, E. C. (2009). AP-3-dependent trafficking and disease: the first decade. Curr. Opin. Cell Biol. 21, 552-559. doi: 10.1016/j.ceb.2009.04.014

Devos, D., Dokudovskaya, S., Williams, R., Alber, F., Eswar, N., Chait, B. T., et al. (2006). Simple fold composition and modular architecture of the nuclear pore complex. Proc. Natl. Acad. Sci. U.S.A. 103, 2172-2177. doi: 10.1073/pnas.0506345103

Diefenbacher, M., Thorsteinsdottir, H., and Spang, A. (2011). The Dsl1 tethering complex actively participates in soluble NSF (N-ethylmaleimide-sensitive factor) attachment protein receptor (SNARE) complex assembly at the endoplasmic reticulum in Saccharomyces cerevisiae. J. Biol. Chem. 286, 25027-25038. doi: 10.1074/jbc.M110.215657

Dodonova, S. O., Diestelkoetter-Bachert, P., von Appen, A., Hagen, W. J., Beck, R., Beck, M., et al. (2015). VESICULAR TRANSPORT. A structure of the COPI coat and the role of coat proteins in membrane vesicle assembly. Science 349, 195-198. doi: 10.1126/science.aab1121

Drin, G., Casella, J. F., Gautier, R., Boehmer, T., Schwartz, T. U., and Antonny, B. (2007). A general amphipathic alpha-helical motif for sensing membrane curvature. Nat. Struct. Mol. Biol. 14, 138-146. doi: 10.1038/ nsmb1194

Dudognon, P., Maeder-Garavaglia, C., Carpentier, J. L., and Paccaud, J. P. (2004). Regulation of a COPII component by cytosolic O-glycosylation during mitosis. FEBS Lett. 561, 44-50. doi: 10.1016/S0014-5793(04)00109-7

Eugster, A., Frigerio, G., Dale, M., and Duden, R. (2000). COP I domains required for coatomer integrity, and novel interactions with ARF and ARF-GAP. EMBO J. 19, 3905-3917. doi: 10.1093/emboj/19.15.3905

Fath, S., Mancias, J. D., Bi, X., and Goldberg, J. (2007). Structure and organization of coat proteins in the COPII cage. Cell 129, 1325-1336. doi: 10.1016/j.cell.2007.05.036

Gillingham, A. K., and Munro, S. (2003). Long coiled-coil proteins and membrane traffic. Biochim. Biophys. Acta Mol. Cell Res. 1641, 71-85. doi: 10.1016/S01674889(03)00088-0

Gillingham, A. K., Sinka, R., Torres, I. L., Lilley, K. S., and Munro, S. (2014). Toward a comprehensive map of the effectors of Rab GTPases. Dev. Cell 31, 358-373. doi: 10.1016/j.devcel.2014.10.007
Grabski, R., Balklava, Z., Wyrozumska, P., Szul, T., Brandon, E., Alvarez, C., et al (2012). Identification of a functional domain within the p115 tethering factor that is required for Golgi ribbon assembly and membrane trafficking. J. Cell Sci. 125, 1896-1909. doi: 10.1242/jcs.090571

Greener, T., Zhao, X., Nojima, H., Eisenberg, E., and Greene, L. E. (2000). Role of cyclin G-associated kinase in uncoating clathrin-coated vesicles from non-neuronal cells. J. Biol. Chem. 275, 1365-1370. doi: 10.1074/jbc.275.2.1365

Guo, Y., and Linstedt, A. D. (2013). Binding of the vesicle docking protein p115 to the GTPase Rablb regulates membrane recruitment of the COPI vesicle coat. Cell. Logist. 3:e27687. doi: 10.4161/cl.27687

He, S., Ni, D., Ma, B., Lee, J. H., Zhang, T., Ghozalli, I., et al. (2013). PtdIns(3)Pbound UVRAG coordinates Golgi-ER retrograde and Atg9 transport by differential interactions with the ER tether and the beclin 1 complex. Nat. Cell Biol. 15, 1206-1219. doi: 10.1038/ncb2848

Hickey, C. M., Stroupe, C., and Wickner, W. (2009). The major role of the Rab Ypt7p in vacuole fusion is supporting HOPS membrane association. J. Biol. Chem. 284, 16118-16125. doi: 10.1074/jbc.M109.000737

Hickey, C. M., and Wickner, W. (2010). HOPS initiates vacuole docking by tethering membranes before trans-SNARE complex assembly. Mol. Biol. Cell 21, 2297-2305. doi: 10.1091/mbc.E10-01-0044

Hirose, H., Arasaki, K., Dohmae, N., Takio, K., Hatsuzawa, K., Nagahama, M., et al. (2004). Implication of ZW10 in membrane trafficking between the endoplasmic reticulum and Golgi. EMBO J. 23, 1267-1278. doi: 10.1038/sj.emboj.7600135

Ho, R., and Stroupe, C. (2015). The HOPS/class C Vps complex tethers membranes by binding to one Rab GTPase in each apposed membrane. Mol. Biol. Cell 26, 2655-2663. doi: 10.1091/mbc.E14-04-0922

Hsia, K. C., and Hoelz, A. (2010). Crystal structure of alpha-COP in complex with epsilon-COP provides insight into the architecture of the COPI vesicular coat Proc. Natl. Acad. Sci. U.S.A. 107, 11271-11276. doi: 10.1073/pnas.1006297107

Jones, S., Newman, C., Liu, F., and Segev, N. (2000). The TRAPP complex is a nucleotide exchanger for Ypt1 and Ypt31/32. Mol. Biol. Cell 11, 4403-4411. doi: $10.1091 / \mathrm{mbc} .11 .12 .4403$

Kamena, F., Diefenbacher, M., Kilchert, C., Schwarz, H., and Spang, A. (2008). Yptlp is essential for retrograde Golgi-ER transport and for Golgi maintenance in S. cerevisiae. J. Cell Sci. 121, 1293-1302. doi: 10.1242/jcs.016998

Kaur, G., and Subramanian, S. (2015). A novel RING finger in the C-terminal domain of the coatomer protein alpha-COP. Biol. Direct 10, 70. doi: 10.1186/s13062-015-0099-9

Kihara, A., Noda, T., Ishihara, N., and Ohsumi, Y. (2001). Two Distinct Vps34 Phosphatidylinositol 3-Kinase complexes function in autophagy and carboxypeptidase Y Sorting inSaccharomyces cerevisiae. J. Cell Biol. 152, 519-530. doi: 10.1083/jcb.152.3.519

Kim, Y. G., Raunser, S., Munger, C., Wagner, J., Song, Y. L., Cygler, M., et al. (2006). The architecture of the multisubunit TRAPP I complex suggests a model for vesicle tethering. Cell 127, 817-830. doi: 10.1016/j.cell.2006.09.029

Kirchhausen, T., and Harrison, S. C. (1984). Structural domains of clathrin heavy chains. J. Cell Biol. 99, 1725-1734. doi: 10.1083/jcb.99.5.1725

Kloepper, T. H., Kienle, C. N., and Fasshauer, D. (2007). An Elaborate classification of SNARE proteins sheds light on the conservation of the Eukaryotic Endomembrane System. Mol. Biol. Cell 18, 3463-3471. doi: 10.1091/mbc.E0703-0193

Krämer, L., and Ungermann, C. (2011). HOPS drives vacuole fusion by binding the vacuolar SNARE complex and the Vam7 PX domain via two distinct sites. Mol. Biol. Cell 22, 2601-2611. doi: 10.1091/mbc.E11-02-0104

Kraynack, B. A., Chan, A., Rosenthal, E., Essid, M., Umansky, B., Waters, M. G., et al. (2005). Dsl1p, Tip20p, and the novel Dsl3(Sec39) protein are required for the stability of the Q/t-SNARE complex at the endoplasmic reticulum in yeast. Mol. Biol. Cell 16, 3963-3977. doi: 10.1091/mbc.E05-01-0056

Kuehn, M. J., Herrmann, J. M., and Schekman, R. (1998). COPII-cargo interactions direct protein sorting into ER-derived transport vesicles. Nature 391, 187-190. doi: $10.1038 / 34438$

Kuhlee, A., Raunser, S., and Ungermann, C. (2015). Functional homologies in vesicle tethering. FEBS Lett. 589, 2487-2497. doi: 10.1016/j.febslet.2015.06.001

Kural, C., Tacheva-Grigorova, S. K., Boulant, S., Cocucci, E., Baust, T., Duarte, D., et al. (2012). Dynamics of intracellular clathrin/AP1- and clathrin/AP3containing carriers. Cell Rep. 2, 1111-1119. doi: 10.1016/j.celrep.2012.09.025

LaGrassa, T. J., and Ungermann, C. (2005). The vacuolar kinase Yck3 maintains organelle fragmentation by regulating the HOPS tethering complex. J. Cell Biol. 168, 401-414. doi: 10.1083/jcb.200407141 
Lee, C., and Goldberg, J. (2010). Structure of coatomer cage proteins and the relationship among COPI, COPII, and clathrin vesicle coats. Cell 142, 123-132. doi: $10.1016 /$ j.cell.2010.05.030

Lee, S. Y., Yang, J.-S., Hong, W., Premont, R. T., and Hsu, V. W. (2005). ARFGAP1 plays a central role in coupling COPI cargo sorting with vesicle formation. J. Cell Biol. 168, 281-290. doi: 10.1083/jcb.200404008

Li, Y., Gallwitz, D., and Peng, R. (2005). Structure-based functional analysis reveals a role for the SM protein Slylp in retrograde transport to the endoplasmic reticulum. Mol. Biol. Cell 16, 3951-3962. doi: 10.1091/mbc.E05-02-0114

Lobingier, B. T., and Merz, A. J. (2012). Sec1/Munc18 protein Vps33 binds to SNARE domains and the quaternary SNARE complex. Mol. Biol. Cell 23, 4611-4622. doi: 10.1091/mbc.E12-05-0343

Lord, C., Bhandari, D., Menon, S., Ghassemian, M., Nycz, D., Hay, J., et al. (2011). Sequential interactions with Sec23 control the direction of vesicle traffic. Nature 473, 181-186. doi: 10.1038/nature09969

Luhtala, N., and Odorizzi, G. (2004). Brol coordinates deubiquitination in the multivesicular body pathway by recruiting Doa4 to endosomes. J. Cell Biol. 166, 717-729. doi: 10.1083/jcb.200403139

Lürick, A., Kuhlee, A., Bröcker, C., Kümmel, D., Raunser, S., and Ungermann, C. (2015). The Habc domain of the SNARE Vam3 interacts with the HOPS tethering complex to facilitate vacuole fusion. J. Biol. Chem. 290, 5405-5413. doi: 10.1074/jbc.M114.631465

Massol, R. H., Boll, W., Griffin, A. M., and Kirchhausen, T. (2006). A burst of auxilin recruitment determines the onset of clathrin-coated vesicle uncoating. Proc. Natl. Acad. Sci. U.S.A. 103, 10265-10270. doi: 10.1073/pnas.0603 369103

Mattheyses, A. L., Atkinson, C. E., and Simon, S. M. (2011). Imaging single endocytic events reveals diversity in clathrin, dynamin and vesicle dynamics. Traffic 12, 1394-1406. doi: 10.1111/j.1600-0854.2011.01235.x

McNew, J. A., Parlati, F., Fukuda, R., Johnston, R. J., Paz, K., Paumet, F., et al. (2000). Compartmental specificity of cellular membrane fusion encoded in SNARE proteins. Nature 407, 153-159. doi: 10.1038/35025000

Meiringer, C. T., Rethmeier, R., Auffarth, K., Wilson, J., Perz, A., Barlowe, C., et al. (2011). The Dsll protein tethering complex is a resident endoplasmic reticulum complex, which interacts with five soluble NSF (N-ethylmaleimide-sensitive factor) attachment protein receptors (SNAREs): implications for fusion and fusion regulation. J. Biol. Chem. 286, 25039-25046. doi: 10.1074/jbc.M110.215327

Murakami, A., Kimura, K., and Nakano, A. (1999). The inactive form of a yeast casein kinase I suppresses the secretory defect of the sec12 mutant. Implication of negative regulation by the Hrr25 kinase in the vesicle budding from the endoplasmic reticulum. J. Biol. Chem. 274, 3804-3810. doi: 10.1074/jbc.274.6.3804

Nakamura, N., Hirata, A., Ohsumi, Y., and Wada, Y. (1997). Vam2/Vps41p and Vam6/Vps39p are components of a protein complex on the vacuolar membranes and involved in the vacuolar assembly in the Yeast Saccharomyces cerevisiae. J. Biol. Chem. 272, 11344-11349. doi: 10.1074/jbc.272.17.11344

Nickerson, D. P., Brett, C. L., and Merz, A. J. (2009). Vps-C complexes: gatekeepers of endolysosomal traffic. Curr. Opin. Cell Biol. 21, 543-551. doi: 10.1016/j.ceb.2009.05.007

Orr, A., Wickner, W., Rusin, S. F., Kettenbach, A. N., and Zick, M. (2015). Yeast vacuolar HOPS, regulated by its kinase, exploits affinities for acidic lipids and Rab:GTP for membrane binding and to catalyze tethering and fusion. Mol. Biol. Cell 26, 305-315. doi: 10.1091/mbc.E14-08-1298

Ostrowicz, C. W., Meiringer, C. T. A., and Ungermann, C. (2008). Yeast vacuole fusion: a model system for eukaryotic endomembrane dynamics. Autophagy 4, 5-19. doi: 10.4161/auto.5054

Parlati, F., McNew, J. A., Fukuda, R., Miller, R., Sollner, T. H., and Rothman, J. E. (2000). Topological restriction of SNARE-dependent membrane fusion. Nature 407, 194-198. doi: 10.1038/35025076

Pols, M. S., van Meel, E., Oorschot, V., ten Brink, C., Fukuda, M., Swetha, M. G., et al. (2013). hVps41 and VAMP7 function in direct TGN to late endosome transport of lysosomal membrane proteins. Nat. Commun. 4, 1361. doi: $10.1038 /$ ncomms 2360

Price, A., Seals, D., Wickner, W., and Ungermann, C. (2000). The docking stage of yeast vacuole fusion requires the transfer of proteins from a cisSNARE complex to a Rab/Ypt protein. J. Cell Biol. 148, 1231-1238. doi: 10.1083/jcb.148.6.1231
Pucadyil, T. J., and Schmid, S. L. (2009). Conserved functions of membrane active GTPases in coated vesicle formation. Science 325, 1217-1220. doi: $10.1126 /$ science. 1171004

Rappoport, J. Z., Kemal, S., Benmerah, A., and Simon, S. M. (2006). Dynamics of clathrin and adaptor proteins during endocytosis. Am. J. Physiol. Cell Physiol. 291, C1072-1081. doi: 10.1152/ajpcell.00160.2006

Rehling, P., Darsow, T., Katzmann, D. J., and Emr, S. D. (1999). Formation of AP-3 transport intermediates requires Vps41 function. Nat. Cell Biol. 1, 346-353. doi: $10.1038 / 14037$

Reilly, B. A., Kraynack, B. A., VanRheenen, S. M., and Waters, M. G. (2001). Golgi-to-endoplasmic reticulum (ER) retrograde traffic in yeast requires Dsllp, a component of the ER target site that interacts with a COPI coat subunit. Mol. Biol. Cell 12, 3783-3796. doi: 10.1091/mbc.12.12.3783

Rein, U., Andag, U., Duden, R., Schmitt, H. D., and Spang, A. (2002). ARF-GAPmediated interaction between the ER-Golgi v-SNAREs and the COPI coat. J. Cell Biol. 157, 395-404. doi: 10.1083/jcb.200112092

Ren, Y., Yip, C. K., Tripath, i,.A., Huie, D., Jeffrey, P. D., Walz, T., and Hughson, F.M. (2009). A structure-based mechanism for vesicle capture by the multisubunit tethering complex Dsl1. Cell 139, 1119-1129. doi: 10.1016/j.cell.2009.11.002

Rothman, J. E., and Orci, L. (1992). Molecular dissection of the secretory pathway. Nature 355, 409-415. doi: 10.1038/355409a0

Sacher, M., Barrowman, J., Schieltz, D., Yates, J. R. III., and Ferro-Novick, S. (2000). Identification and characterization of five new subunits of TRAPP. Eur. J. Cell Biol. 79, 71-80. doi: 10.1078/S0171-9335(04)70009-6

Schmitt, H. D. (2010). Dsl1p/Zw10: common mechanisms behind tethering vesicles and microtubules. Trends Cell Biol. 20, 257-268. doi: 10.1016/j.tcb.2010.02.001

Seals, D. F., Eitzen, G., Margolis, N., Wickner, W. T., and Price, A. (2000). A Ypt/Rab effector complex containing the Secl homolog Vps33p is required for homotypic vacuole fusion. Proc. Natl. Acad. Sci. U.S.A. 97, 9402-9407. doi: 10.1073/pnas.97.17.9402

Shindiapina, P., and Barlowe, C. (2010). Requirements for transitional endoplasmic reticulum site structure and function in Saccharomyces cerevisiae. Mol. Biol. Cell 21, 1530-1545. doi: 10.1091/mbc.E09-07-0605

Söllner, T., Whiteheart, S. W., Brunner, M., Erdjument-Bromage, H., Geromanos, S., Tempst, P., et al. (1993). SNAP receptors implicated in vesicle targeting and fusion. Nature 362, 318-324. doi: 10.1038/362318a0

Stroupe, C., Collins, K. M., Fratti, R. A., and Wickner, W. (2006). Purification of active HOPS complex reveals its affinities for phosphoinositides and the SNARE Vam7p. EMBO J. 25, 1579-1589. doi: 10.1038/sj.emboj.7601051

Suckling, R. J., Poon, P. P., Travis, S. M., Majoul, I. V., Hughson, F. M., Evans, P. R., et al. (2015). Structural basis for the binding of tryptophanbased motifs by $\delta$-COP. Proc. Natl. Acad. Sci. U.S.A. 112, 14242-14247. doi: $10.1073 /$ pnas. 1506186112

Sun, B., Chen, L., Cao, W., Roth, A. F., and Davis, N. G. (2004). The yeast casein kinase Yck3p is palmitoylated, then sorted to the vacuolar membrane with AP3-dependent recognition of a YXXPhi adaptin sorting signal. Mol. Biol. Cell 15, 1397-1406. doi: 10.1091/mbc.E03-09-0682

Suvorova, E. S., Duden, R., and Lupashin, V. V. (2002). The Sec34/Sec35p complex, a Yptlp effector required for retrograde intra-Golgi trafficking, interacts with Golgi SNAREs and COPI vesicle coat proteins. J. Cell Biol. 157, 631-643. doi: $10.1083 /$ jcb.200111081

ter Haar, E., Musacchio, A., Harrison, S. C., and Kirchhausen, T. (1998). Atomic Structure of Clathrin: a $\beta$ Propeller Terminal Domain Joins an $\alpha$ Zigzag Linker. Cell 95, 563-573. doi: 10.1016/S0092-8674(00)81623-2

Trahey, M., and Hay, J. C. (2010). Transport vesicle uncoating: it's later than you think. F1000 Biol. Rep. 2:47. doi: 10.3410/B2-47

Tripathi, A., Ren, Y., Jeffrey, P. D., and Hughson, F. M. (2009). Structural characterization of Tip20p and Dsl1p, subunits of the Dsl1p vesicle tethering complex. Nat. Struct. Mol. Biol. 16, 114-123. doi: 10.1038/nsmb.1548

Ungewickell, E., Ungewickell, H., Holstein, S. E., Lindner, R., Prasad, K., Barouch, W., et al. (1995). Role of auxilin in uncoating clathrin-coated vesicles. Nature 378, 632-635. doi: 10.1038/378632a0

VanRheenen, S. M., Reilly, B. A., Chamberlain, S. J., and Waters, M. G. (2001). Dsllp, an essential protein required for membrane traffic at the endoplasmic reticulum/Golgi interface in yeast. Traffic 2, 212-231. doi: 10.1034/j.16000854.2001.020307.x 
Wang, J., Davis, S., Menon, S., Zhang, J., Ding, J., Cervantes, S., et al. (2015). Ypt1/Rab1 regulates Hrr25/CK1delta kinase activity in ER-Golgi traffic and macroautophagy. J. Cell Biol. 210, 273-285. doi: 10.1083/jcb.201408075

Wang, T., Grabski, R., Sztul, E., and Hay, J. C. (2015). p115-SNARE interactions: a dynamic cycle of p115 binding monomeric SNARE motifs and releasing assembled bundles. Traffic 16, 148-171. doi: 10.1111/tra.12242

Wang, W., Sacher, M., and Ferro-Novick, S. (2000). TRAPP stimulates guanine nucleotide exchange on Yptlp. J. Cell Biol. 151, 289-296. doi: 10.1083/jcb.151.2.289

Wassmer, T., Attar, N., Harterink, M., van Weering, J. R., Traer, C. J., Oakley, J., et al. (2009). The retromer coat complex coordinates endosomal sorting and dynein-mediated transport, with carrier recognition by the trans-Golgi network. Dev. Cell 17, 110-122. doi: 10.1016/j.devcel.2009. 04.016

Waters, M. G., Clary, D. O., and Rothman, J. E. (1992). A novel 115-kD peripheral membrane protein is required for intercisternal transport in the Golgi stack. J. Cell Biol. 118, 1015-1026. doi: 10.1083/jcb.118.5.1015

Whyte, J. R., and Munro, S. (2002). Vesicle tethering complexes in membrane traffic. J. Cell Sci. 115, 2627-2637.

Yamasaki, A., Menon, S., Yu, S., Barrowman, J., Meerloo, T., Oorschot, V., et al. (2009). mTrs130 is a component of a mammalian TRAPPII complex, a Rab1 GEF that binds to COPI-coated vesicles. Mol. Biol. Cell 20, 4205-4215. doi: 10.1091/mbc.E09-05-0387

Yu, I. M., and Hughson, F. M. (2010). Tethering factors as organizers of intracellular vesicular traffic. Annu. Rev. Cell Dev. Biol. 26, 137-156. doi: 10.1146/annurev.cellbio.042308.113327

Yu, S., Satoh, A., Pypaert, M., Mullen, K., Hay, J. C., and Ferro-Novick, S. (2006). $\mathrm{mBet} 3 \mathrm{p}$ is required for homotypic COPII vesicle tethering in mammalian cells. J. Cell Biol. 174, 359-368. doi: 10.1083/jcb.200603044
Zick, M., and Wickner, W. (2012). Phosphorylation of the effector complex HOPS by the vacuolar kinase Yck3p confers Rab nucleotide specificity for vacuole docking and fusion. Mol. Biol. Cell 23, 3429-3437. doi: 10.1091/mbc.E1204-0279

Zink, S., Wenzel, D., Wurm, C. A., and Schmitt, H. D. (2009). A link between ER tethering and COP-I vesicle uncoating. Dev. Cell 17, 403-416. doi: 10.1016/j.devcel.2009.07.012

Zlatic, S. A., Tornieri, K., L'Hernault, S. W., and Faundez, V. (2011a). Clathrin-dependent mechanisms modulate the subcellular distribution of class C Vps/HOPS tether subunits in polarized and nonpolarized cells. Mol. Biol. Cell 22, 1699-1715. doi: 10.1091/mbc.E1010-0799

Zlatic, S. A., Tornieri, K., L'Hernault, S. W., and Faundez, V. (2011b). Metazoan cell biology of the HOPS tethering complex. Cell. Logist. 1, 111-117. doi: 10.4161/cl.1.3.17279

Zolov, S. N., and Lupashin, V. V. (2005). Cog3p depletion blocks vesicle-mediated Golgi retrograde trafficking in HeLa cells. J. Cell Biol. 168, 747-759. doi: $10.1083 /$ jcb. 200412003

Conflict of Interest Statement: The authors declare that the research was conducted in the absence of any commercial or financial relationships that could be construed as a potential conflict of interest.

Copyright (C) 2016 Schröter, Beckmann and Schmitt. This is an open-access article distributed under the terms of the Creative Commons Attribution License (CC BY). The use, distribution or reproduction in other forums is permitted, provided the original author(s) or licensor are credited and that the original publication in this journal is cited, in accordance with accepted academic practice. No use, distribution or reproduction is permitted which does not comply with these terms. 